\title{
Blog Post about Distinguishing Doublets
}

\author{
Yuxuan Zhou \\ University of Toronto, Ontario, Canada \\ Email: zhouyuxuan0411@gmail.com
}

How to cite this paper: Zhou, Y. X. (2022). Blog Post about Distinguishing Doublets. Open Journal of Modern Linguistics, 12, 23-28.

https://doi.org/10.4236/ojml.2022.121003

Received: December 23, 2021

Accepted: January 21, 2022

Published: January 24, 2022

Copyright $\odot 2022$ by author(s) and Scientific Research Publishing Inc. This work is licensed under the Creative Commons Attribution International License (CC BY 4.0).

http://creativecommons.org/licenses/by/4.0/

\begin{abstract}
What makes English such a globally prominent language? As we all know, the English vocabulary is huge! However, what makes English such a globally prominent language? The reason is English borrowing words from many different languages. English borrows the most from Latin, French and Greek. There are also words that are native to English. This electronic document is a kind of Blog Post. In this paper, you can see the magic change processes of English and know how to identify doublets in different languages and what sound changes occurred between PIE and its descendant languages through this paper by using the comparative method.
\end{abstract}

\section{Keywords}

Linguistic, Latin English, Germantic English, PIE, Comparative Method, Language Study, Doublets, English's Change Processes, Borrow Words, Native, Etymology, PIE Roots, Consonant Change, Blog Post

\section{Background}

English has borrowed words from many, many languages! For instance: Latin, French, Greek, German, and so on. The full table shows in Figure 1. Among these languages, Latin is the language that has heavily influenced English. However, English is not a Romance language. It is Germanic. Specifically, it is West Germanic. Therefore, we can estimate that there are some huge relationships between English words and other words.

The comparative method is a technique that examines sound correspondences between languages to determine if words belonging to these languages are related to each other, and if so, what their common ancestor language must have looked like. This technique can also be used to determine if a set of words are doublets, i.e., words in the same language which share a common ancestor, but entered the language through different paths. 


\begin{tabular}{|lll|}
\hline Latin & Italian & Hindi-Urdu \\
French & Dutch & Slovak \\
Greek & Arabic & Ojibwe \\
Old Norse & Yiddish & Tamil \\
German & Persian & Finnish \\
Spanish & Czech & Korean \\
Norwegian & Polish & Russian \\
\hline
\end{tabular}

Figure 1. The languages that English has borrowed words from.

In this article, I have used 1) reconstructed Proto-Indo-European (PIE) roots and 2) the knowledge of regular sound changes that occurred between PIE and its descendant languages (mainly Germanic, Latin and Greek) to clearly identify words in English that are doublets. For instance, by knowing about the sound change processes that took place between PIE to Germanic and PIE to Latin, I were able to observe that the English word chef (borrowed from French) and the English word head (inherited from Germanic) both descend from the PIE root *kaput.

For this article, I am going to write a "blog post" that instructs readers how to identify doublets in English by knowing about the sound changes (or lack thereof) that occurred between PIE to Germanic and PIE to Latin. The goal of this article is to give our readers the tools that they can use to be able to identify English doublets and even develop the ability to write and orally present linguistic concepts.

\section{Introduction}

\subsection{List of Native English Words}

I will demonstrate to readers how to identify English doublets by giving them two examples. The following list are native English words, I will pick two wordforms to use as my examples which are $<$ film $>$ and $\langle$ cold $\rangle$. These two words are short, commonly used in modern English and having basic meanings. They are suitable to present linguistic concepts to different kinds of audiences.

\begin{tabular}{|lll|}
\hline beetle $^{1}$ & fang (lower case) & tame \\
bloom $^{2}$ & film & teach \\
cold & hew & thread \\
crow & hollow & thirst \\
\hline
\end{tabular}

\subsection{Tools and Instructions}

1) Use the American Heritage Dictionary (5th) (AHD) to look up the meaning of the word. Record the word's form and meaning, and the form of the word at one other stage in its development within English (i.e., its form in Middle English, Old English, or Germanic).

2) Use the Indo-European Roots Appendices in the AHD to identify the PIE root that this native English word descends from. Record both the form and meaning of this root. 
3) After identified the PIE root in the Indo-European Roots Appendices, scroll down and find another word in English that also descends from this PIE root, but which entered English through Latin. I will record the form and meaning of this borrowed English word and the form and meaning of the Latin word it comes from.

4) Using the textbook (see Figure 2), show that the native English word and the borrowed Latinate word descend from the same PIE root by describing sound change processes that led these words to have different forms. In other words, you need to: a) Describe one sound change process that took place between PIE and Germanic which played a role in determining the form of the native English word. Identify which segment(s) in the word underwent this change. b) Describe one sound change process that took place between PIE and Latin which played a role in determining the form of the borrowed Latinate word. Identify which segment(s) in the word underwent this change.

\begin{tabular}{|c|c|c|c|}
\hline$P I E$ & Greek & Latin & English \\
\hline${ }^{*} \mathrm{p}$ & $\mathrm{p}$ & $\mathrm{p}$ & $f(v)$ \\
\hline$*_{t}$ & $\mathrm{t}$ & $\mathrm{t}$ & th \\
\hline${ }^{*} k, k$ & c & c & $\mathrm{h}$ (gh) \\
\hline${ }^{*} k^{w}$ & $p, t, c$ & $q u$ & wh \\
\hline *b & b & b & $\mathrm{p}$ \\
\hline${ }^{*} \mathrm{~d}$ & d & $\mathrm{d}$ & $\mathrm{t}$ \\
\hline${ }^{*} \mathrm{~g}, \mathrm{~g}$ & g & g & $\mathrm{c}, \mathrm{k}(\mathrm{ch})$ \\
\hline${ }^{*} \mathbf{g}^{\mathbf{w}}$ & $\mathrm{b}, \mathrm{d}(\mathrm{g})$ & $\mathbf{v}(\mathrm{gu})$ & $q u$ \\
\hline *bh & $\mathrm{ph}$ & $f(b)$ & $\mathrm{b}(\mathrm{v})$ \\
\hline${ }^{*} \mathrm{dh}$ & th & $f(d)$ & $\mathrm{d}$ \\
\hline *'gh, gh & ch & $h(g)$ & $g(y)$ \\
\hline${ }^{*} g^{w h}$ & $\mathrm{ph}$, th (ch) & $f(v)$ & $\mathbf{w}$ \\
\hline$*_{s}$ & $h, s$ & $s, r$ & $\mathbf{s}$ \\
\hline${ }^{*} \mathrm{H}_{\mathrm{e}}$ & $e,-$ & $a,-$ & $a,-$ \\
\hline${ }^{*} \mathrm{H}_{\mathrm{a}}$ & $a,-$ & $a,-$ & $a,-$ \\
\hline${ }^{*} \mathrm{H}_{\mathrm{o}}$ & $0,-$ & $a,-$ & $a,-$ \\
\hline${ }^{*} \mathrm{~m}$ & $\mathbf{m}$ & $\mathbf{m}$ & $\mathbf{m}$ \\
\hline${ }^{*} \mathrm{~m}$ & $\mathbf{a}$ & em & um \\
\hline${ }^{*} \mathrm{n}$ & $\mathbf{n}$ & $\mathbf{n}$ & $\mathrm{n}$ \\
\hline${ }^{*}$ n & $\mathbf{a}$ & en & un \\
\hline${ }^{*} 1$ & 1 & 1 & 1 \\
\hline$* 1$ & al (la) & ul & $\mathrm{ul}$ \\
\hline${ }^{*} \mathbf{r}$ & $\mathbf{r}$ & $\mathbf{r}$ & $\mathbf{r}$ \\
\hline${ }^{*} \mathrm{r}$ & ar (ra) & or & ur \\
\hline${ }^{*} w$ & $-(\mathrm{h})$ & $\mathbf{v}$ & $\mathbf{w}$ \\
\hline${ }^{*} y$ & $\mathrm{z}(\mathrm{h})$ & $\mathbf{j}$ & $y$ \\
\hline
\end{tabular}

Figure 2. Consonant correspondences for PIE, Greek, Latin, and English. 
5) When describing a sound change process, make sure to include the name of the sound change process (if there is one), a description of the sound change process, and identify which part of the word exhibits this process. For instance, if I was explaining how we can tell that the words captain and head are doublets, I would focus on the initial consonants of each word and explain what changes (or lack of changes) occurred between PIE to Germanic and PIE to Latin which led to their present-day forms of these words.

\section{Body Paragraph}

\subsection{Example $1-<$ Film $>$}

Firstly, let us see the word $\langle$ film $>$. Based on the information from American Heritage Dictionary, the primary definition of $<$ film $>$ is a thin skin or membrane. This word is cognated with filmen in Old English ("Film", The American Heritage Dictionary (Ed.), 2020). In AED, the PIE root "pel-" that still descends to this native English word $-<$ film $>$. This root means skin or hide. We can find its origin is from Germanic suffixed form ${ }^{*}$ fil-men-ja. Then, in the same section, the word $<$ pellicle $>$ has the same PIE root and borrowed from Latin to English. In English, <pellicle> means a thin skin or film, such as a membrane or liquid film ("Pellicle", The American Heritage Dictionary (Ed.), 2020).

The form of these words is from the Latin word pellicula. The meaning of this Latin word is husk and diminutive of skin. To see the PIE root "pel-", we know that it is the suffixed form ${ }^{*}$ pel-ni. Therefore, we can make a conclusion first, the native English word is $<$ film $>$. Then, the borrowed word $<$ pellicle $>$ has the same PIE root as $<$ film $>$. The reason why they have different forms is the sound change between PIE and Germanic or PIE and Latin are different. There is a rule called "spirantization" in Grimm's Law which means "when the initial consonant is a voiceless stop, it will turn into fricatives in Germanic". So, $* / p /$ in PIE will change to /f/ in Germanic. In contrast, through Figure 2, we can see that the initial consonant $* / \mathrm{p} /$ is still $/ \mathrm{p} /$ in Latin. Hence, the borrowed word from Latin is start with a sound $/ \mathrm{p} /$ as well.

Above all, by focusing on the initial consonant change of these two words, we know that the initial consonant of both $<$ film $>$ and $<$ pellicle $>$ became a $/ \mathrm{p} /$ after their sound change process respectively. It is possible for these two words descend from the same PIE root, they have the common root, but entered English from Native English word and borrowed from Latin. As a result, $<$ film $>$ and $<$ pellicle $>$ are doublets.

\subsection{Example $2-<$ Cold $>$}

The other example is $\langle$ cold $>$, the primary definition of the noun form is "the feeling resulting from lack of warmth; chill" ("Cold", The American Heritage Dictionary (Ed.), 2020). This word cognates with ceald from Old English. In order to find its doublet, we have the following steps. The first step is to find the PIE root of < cold $>$ through AED. In Figure 2, Indo-European roots, "gel-" is the 
correct PIE root and the meaning of it is "cold; to freeze". The form of "gel-" is ${ }^{*}$ kaldaz in Germanic. The second step is to find another word that has the same PIE root but is descended from Latin. I chose the English word <glacial> which has the definition of "extremely cold; icy" and this is a synonym of cold ("Glacial", The American Heritage Dictionary (Ed.), 2020). This world comes from Latin, which had various forms, like glaciālis, glaciēs, through Old French -icy.

In addition, the definition of the Latin word is ice and it is a suffixed zero-grade form ${ }^{{ }}$gl-k-. The final step is to find each of their sound change processes. Let us focus on the initial consonant change of them. According to Figure 2, the consonant ${ }^{*} / \mathrm{g} /$ in PIE turns into $/ \mathrm{k} /$ in Germanic. This correspondence is called devoicing which means if the PIE root is a voiced (non-aspirated) stop, it will become voiceless in Germanic. Thus, in present-day English, the sound $/ \mathrm{k} /$ in the word $<$ cold $>$ is same as the sound $/ \mathrm{g} /$ in past. Comparison with the sound change between PIE and Germanic, the consonant ${ }^{*} / \mathrm{g} /$ in PIE root is still /g/ in Latin. There is still a small change, as we mentioned before, there is an ablaut change which means -o- sometimes changes into -e-, and -e- sometimes disappears called zero-grade form. In this example, the PIE root "gel-" cut the letter e and become "gl-". However, there is no effect to the initial consonant. Hence, we can prove that both $<$ cold $>$ and $<$ glacial $>$ has the same pronunciation /g/ from different sound change, so they have the same PIE root. If two words share the same etymological root in one language, but have different histories called doublets. Since $<$ cold $>$ and $<$ glacial $>$ are both descended from the same PIE root, and one from native English words and the other from Latin, they are doublets.

\section{Conclusion}

In conclusion, when two words share the same etymological root in one language, but have different histories called doublets. So, we can use the sound change to make sure whether or not two words descend from the same PIE root. Language is very interesting, and English was influenced by every stage in the development from Latin to modern-day French (As Figure 3 shows). Through

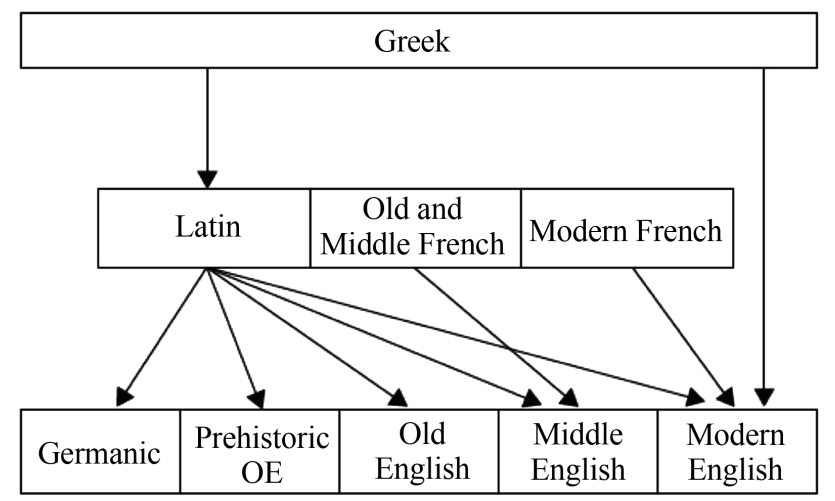

Figure 3. Major paths of borrowing from Greek and Latinate sources into English. 
this paper, we can better understand more about the systematic and patterned nature of language and we can analyze and learn new English words in the future. Studying the etymology is a good way to study languages! It helps us to interpret the history of the language-speaking places, identify patterns of sound change in word formation over time, and identify different ways in which the meaning of words can change over time. Language learning is an interesting but difficult period, wish everyone can get some fun during studies.

\section{Conflicts of Interest}

The author declares no conflicts of interest regarding the publication of this paper.

\section{References}

Cold, The American Heritage Dictionary (Ed.) (2020). https://ahdictionary.com/word/search.html?q=cold\&submit.x=0\&submit.y=0

Film, The American Heritage Dictionary (Ed.) (2020). https://ahdictionary.com/word/search.html?q=film\&submit.x=0\&submit.y=0

Glacial, The American Heritage Dictionary (Ed.) (2020). https://ahdictionary.com/word/search.html?q=glacial\&submit.x=0\&submit.y $=0$

Pellicle, The American Heritage Dictionary (Ed.) (2020). https://ahdictionary.com/word/search.html?q=pellicle\&submit.x=32\&submit.y=13 